\title{
In vivo growth fluorometry: accuracy and limits of microalgal growth rate measurements in ecophysiological investigations
}

\author{
Lydia Gustavs*, Rhena Schumann, Anja Eggert, Ulf Karsten
}

University of Rostock, Department of Biological Sciences-Applied Ecology, Albert-Einstein-Straße 3, 18051 Rostock, Germany

\begin{abstract}
In vivo growth fluorometry (Karsten et al. 1996) is based on the sensitive detection of in vivo chlorophyll a (chl a) fluorescence and monitors its increase over time as an indicator for growth. The method offers a simple, rapid, non-invasive, reproducible and calibration-free measurement of growth rates in unialgal cultures and facilitates multifactorial ecophysiological studies on algal cultures. The technical setup is well suited for use on benthic, adhering, filamentous and colonyforming microalgae. Low detection limits avoid self-shading and nutrient limitation during growth rate determination. Acclimated growth rates should be measured after a pre-incubation phase of 1 to $3 \mathrm{~d}$. A broad data set correlating in vivo chl a fluorescence with cell number, organic carbon and chl a concentration in representative members of the Cyanobacteria, Rhodophyta, Chlorophyta and Bacillariophyceae is presented. A calibration of chl a fluorescence is not required for acclimated growth rate measurements of Bacillariophyceae and Chlorophyta but is recommended for high abundances of Cyanobacteria and Rhodophyta.
\end{abstract}

KEY WORDS: Growth rate Chlorophyll a fluorescence $\cdot$ Adhering algae $\cdot$ Multifactorial ecophysiological studies

Resale or republication not permitted without written consent of the publisher

\section{INTRODUCTION}

Growth and reproduction typically characterise ecological success of species under given environmental conditions and can be inferred from natural occurrence or investigated using multifactorial growth experiments. In contrast to most multicellular organisms, growth rates of microalgae are dominated by cell division, in many cases binary fission. Under the respective optimum conditions, there are slow- or fast-growing species. Consequently, growth rates also reflect life strategies and performance of microorganisms. While slowly proliferating taxa tend to be k-strategists with low mortality rates, long life spans and efficient resource utilization capacities, so-called r-strategists are fast-dividing pioneer colonisers (MacArthur \& Wilson 1967). Environmental factors strongly influence growth rates and, hence, limit dispersal and population size at the tolerance limits of a species. From an ecological perspective, growth rate-in con- trast to cellular processes such as photosynthesis, respiration and anabolic pathways - represents the most relevant process to describe the potential performance of species in their ecosystem. The precise determination of growth rates under different abiotic or stress conditions is the first fundamental step to evaluate tolerance limits, growth optima and adaptation abilities of specific algal strains.

Since calculations of microalgal growth rates are commonly based on cell counts, abundance determination by hematocytometer chambers is a widely used method to obtain growth data. However, this laborious method is not suitable for benthic, adhering, filamentous or colony-forming species, which are not evenly distributed and thus escape the regular harvest of subsampling. Although automated cell counts, e.g. using a Coulter counter or image analysis systems (Brown et al. 1989), are more time-efficient for suspensions of unicellular algae, they are not suitable for morphologically complex organisms either. The direct (microscop- 
ical) determination of abundance is often replaced by cellular biomass markers, such as chlorophyll a (chl a), carbon, ATP or proteins (Stein 1973, Butterwick et al. 1982, Becker 1994 and references therein). Disadvantages of using these biomarkers are related to incomplete extraction procedures, calibration protocols and the specificity of the test methods (for discussion see Wright et al. 1997). Moreover, the absolute concentration of biomass parameters is influenced by abiotic parameters such as radiation or nutrient supply, and by culture age, physiology and size of cells (Kruskopf \& Flynn 2006). In laboratory cultures these factors can be controlled, while respective data obtained in field studies must be evaluated by taking into account alterations in community structure and variation in abiotic parameters. Furthermore, the use of carbon or protein content as algal biomass equivalents is hampered by co-occurring bacteria or organic exudates.

Growth of colonial or filamentous organisms can be determined gravimetrically as dry mass (e.g. GarciaPichel et al. 1992). Packed cell volume measurements offer a similar approach, as algal samples are centrifuged in scaled capillary tubes and their abundance is determined as biomass by volume. However, dry mass and packed cell volume include any contamination such as bacteria or suspended particles and, hence, falsify the results.

The most widespread in vivo method in culture studies is the determination of absorbance (optical density) at a given wavelength. It is a simple and non-invasive method for measuring microbial abundance. Optical density is commonly defined as $\log _{10}\left(I_{0} / I_{\mathrm{t}}\right)$, i.e. the logarithm to the base 10 of the ratio of incident light $I_{0}$ to transmitted light $I_{\mathrm{t}}$. Absorptance is defined as the ratio of absorbed to incident light $\left(I_{\mathrm{a}} / I_{0}\right)$ and, therefore, linear to abundance. Accordingly, absorbance equals $-\log _{10}$ (1-absorptance). The logarithmic correlation between absorptance and optical density must be taken into consideration by evaluating respective data, i.e. measurements are only valuable for the range where both parameters show almost linearity. At low cell numbers, variation in abundance causes only small changes in optical density, making it very sensitive to contaminating particles, while at high abundances small changes in cell numbers cause large deviations in optical density. Additionally, serious self-shading occurs at high abundances. Thus, the method is not precise at low cell numbers even though the initial abundance $\mathrm{N}_{0}$ is essential for the calculation of the growth rate. At moderate and high cell densities (optical density $>0.7$ ), the method requires a dilution step in order to ensure that measurements fall within the region of linear correlation. Moreover, optical density determinations are generally not specific to algal suspension because any accompanying precipitate (e.g. due to $\mathrm{pH}$ change during growth) or bacterial contamination would interfere (Butterwick et al. 1982). Furthermore, the scattering coefficient, which is indispensable for the correct use of the method, is a complex function of cell size, shape and presence of scattering substances, and depends on the statistical distribution of the algal cells in solution (e.g. Becker 1994). Another disadvantage is related to the sedimentation of cells in the curettes, which leads to an underestimation of their abundance. Nonetheless, optical density measurements are not suitable for benthic and adhering microalgae.

Brand et al. (1981) reported on a device that simultaneously measures chl a fluorescence in about 300 unialgal cultures as an indicator for growth. The basic assumptions of the method are that the fluorescence yield of a culture in balanced growth is linearly correlated with cell number and that it is detectable over a wide range of cell densities (Wood et al. 2005). The method has been applied to a wide range of microalgal groups under a wide range of conditions (Wood et al. 2005 and references therein), but it requires uniform suspension of the organisms in the culture and thus is not suitable for highly clumped suspensions or organisms that adhere to the walls of culture vessels. The method presented by Karsten et al. (1996) focuses on in vivo fluorometric growth measurements for benthic, adhering, filamentous and colony-forming organisms that are not captured by other methods and even allows growth measurements on solid substrata such as agar plates (Gustavs et al. in press). As petri dishes are placed into the measuring setup and chl a fluorescence is determined within seconds, daily subsampling and tedious sample processing is not required. Therefore, fluorometric growth measurements are a good alternative or complement to traditional methods.

The objective of the present study was to investigate the potential of in vivo growth fluorometry as an ecophysiological method for a wide range of phototrophic microorganisms with an emphasis on benthic, colonyforming species and biofilm producers. A broad data set is presented by correlating in vivo chl a values with traditional biomass proxies such as cell number, organic carbon and chl a concentration in representative members of the Cyanobacteria, Rhodophyta, Chlorophyta and Bacillariophyceae, which differ in accessory pigment composition, cellular chl a concentration, cell size and morphology. Minimum (detection limit) and maximum cell numbers (avoidance of self-shading) were evaluated, and growth rates calculated by an iterative optimisation process including up to 7 logarithmic data points. The time period for chl a value acclimation was followed after a strong increase in photosynthetically active radiation (PAR, 400 to $700 \mathrm{~nm})$. 


\section{MATERIALS AND METHODS}

Organisms and culture conditions. Thirteen microalgal strains with different taxonomic assignment and contrasting morphological characteristics were investigated (Table 1). The aquatic chlorophyceae Desmodesmus subspicatus ROS-DZBK 33, the aeroterrestrial trebouxiophyceae 'Chlorella' trebouxioides SAG 2142, SAG 2143, 'Chlorella' luteoviridis SAG 2196 and Stichococcus sp. SAG 2059 and SAG 2060 (ROS: University of Rostock culture collection; SAG: University of Göttingen culture collection) were grown in modified Bold's basal medium (MBBM) (Starr \& Zeikus 1993, BBM modified by addition of triple nitrate concentration) at $20^{\circ} \mathrm{C}$ and 35 to $40 \mu \mathrm{mol}$ photons $\mathrm{m}^{-2} \mathrm{~s}^{-1}$ in aerated pre-cultures. The cyanobacterial strains Coleofasciculus chthonoplastes (formerly Microcoleus chthonoplastes, Siegesmund et al. 2008) ROS-WW 11 and ROS-WW 6 were grown in sterile filtered Baltic Sea water (membrane filter, $0.2 \mu \mathrm{m}$, NL16, Schleicher \& Schuell) adjusted to a salinity of 33 (hw Meersalz professional) and enriched with $\mathrm{f} / 2$ (Guillard 1975 ) at $24^{\circ} \mathrm{C}$ and $22 \mu \mathrm{mol}$ photons $\mathrm{m}^{-2} \mathrm{~s}^{-1}$ without aeration. The cyanobacterial strain Synechocystis sp. PCC 6803 (PCC: Pasteur culture collection) was grown in BG 11 (Sigma-Aldrich) at $24^{\circ} \mathrm{C}$ and $22 \mu \mathrm{mol}$ photons $\mathrm{m}^{-2} \mathrm{~s}^{-1}$ with aeration. The red algae Dixoniella grisea UTEX 2320 (UTEX: University of Texas culture collection) and Porphyridium sp. JW 4126 (JW: John West culture collection, University of Melbourne) were grown in sterile Baltic Sea water adjusted to a salinity of 33 and enriched with full-strength Provasoli's nutrients (Starr \& Zeikus 1993) at $20^{\circ} \mathrm{C}$ and $35 \mu \mathrm{mol}$ photons $\mathrm{m}^{-2} \mathrm{~s}^{-1}$ without aeration. The Arctic diatom strains Nitzschia cf. aurariae ROS-KD 03 and Cylindrotheca closterium ROS-KD 10 were grown in sterile Baltic Sea water adjusted to a salinity of 33 enriched with $\mathrm{f} / 2$ medium (Guillard 1975) at $5^{\circ} \mathrm{C}$ and $10 \mu \mathrm{mol}$ photons $\mathrm{m}^{-2} \mathrm{~s}^{-1}$ without aeration. The temperature deviation in the climate chambers was $\pm 1^{\circ} \mathrm{C}$. While the diatoms were grown under continuous light to reflect Arctic summer conditions, all other species were kept on a $16 \mathrm{~h}$ light:8 h dark cycle; Osram Daylight Lumilux Deluxe lamps were used as light sources. Radiation measurements were carried out with a Li-Cor LI-190-SB cosine-corrected sensor connected to a Li-Cor LI-1000 data logger (Lambda Instruments) at the bottom of the petri dishes (sensor error $<2 \%$ ).

Growth fluorometer. Fluorescence measurements were performed with a growth fluorometer according to Karsten et al. (1996). Bright blue light-emitting diodes (LEDs, Nichia) with a peak wavelength at $470 \mathrm{~nm}$ were selected for exciting the chl a fluorescence.

Experimental setup. The LEDs were switched on 20 min before starting each measurement to obtain a constant excitation signal. The modulated LEDs of the Hansatech fluorometer were controlled by a 9 position rotary light source intensity (LSI), which offers the possibility to regulate radiation intensity. In all experiments, the lowest possible LSI was chosen, which gave a significant signal at Day 0 depending on the phototrophic organism investigated. The gain controlling the amplification of the detected signal was standardized with $20 \mathrm{ml}$ of a $1 \mathrm{mg} \mathrm{l}^{-1}$ rhodamine B solution. This signal represented the maximum (100\%) value and was adjusted to $1700 \mathrm{mV}$. The minimum $(0 \%)$ value was set by adjusting daily the respective medium blanks to zero. The medium blank represented the minimum $(0 \%)$ value; thus, the system was always 2-point calibrated.

Fluorescence measurements. Disposable petri dishes with cover lids (Licefa) were used as incubation vessels. All measurements started with log-phase cultures, which were adapted to the respective abiotic conditions. These conditions were not changed during the growth rate determination. Twenty $\mathrm{ml}$ of each culture (initial cell number $=$ lower detection limit, see Table 2) were transferred to petri dishes under sterile conditions and sealed with parafilm (Pechiney Plastic Packaging). As the illumination and detection setup was placed on the bottom of the petri dish, cells needed to sediment and dark-adapt before the first fluorescence reading was recorded. Single measurements were performed within seconds by placing the petri dish into the detection setup, without causing resuspension, to keep non-adhering cells on the bottom of the petri dish within the optimum detection layer. For all species grown at a $16 \mathrm{~h}$ light:8 $\mathrm{h}$ dark cycle, the chl a fluorescence was regularly measured every $24 \mathrm{~h}$. For the diatoms, which were kept under continuous irradiation and hence exhibited fast growth $\left(\mu>1 \mathrm{~d}^{-1}\right)$, the measurement interval was reduced to $12 \mathrm{~h}$. All incubations were performed in triplicate.

Linear relationship between chl a fluorescence and biomass parameters. As the exponential growth model is based on the dichotomy of cells, it is traditionally applied to cell numbers. Therefore, the measured chl $a$ fluorescence was correlated with cell number and biomass parameters (chl $a$, carbon). Four to 5 dilution steps of a microalgal culture were prepared in triplicate. The fluorescence signals of this dilution series were measured as mentioned above. From each dilution step, another set (in triplicate at a minimum) was measured for cell numbers (if possible), chl a concentration and organic carbon content. For the unicellular organisms, $1 \mathrm{ml}$ suspension was fixed in $0.05 \mathrm{ml}$ glutardialdehyde (final concentration of $1.2 \%$ ) and $\geq 400$ cells were counted in a Bürker blood counting chamber in 3 replicates at 200× magnification (Olympus BH-2). Porphyridium sp. was counted in sedimentation chambers of $1 \mathrm{ml}$ without replicates. Cell numbers of the filamentous Coleofasciculus chthonoplastes were determined by measuring filament length and dividing that 
value by the median of single cell length. Ten to 30 filaments were measured in a Bürker blood counting chamber in 3 replicates at 10× magnification (Olympus $\mathrm{BH}-2)$. The colony-forming Dixoniella grisea was not calibrated against cell numbers but against organic carbon and chl a concentration (see Table 2).

Growth rate calculation. Calculation of the growth rate $\mu$ using the equation $F_{t}=F_{0} e^{\mu t}\left(F_{0}\right.$ : initial fluorescence; $F_{t}$ : fluorescence after $t$ days) requires exponential growth. To determine whether the cultures were in the exponential growth phase, logarithmic fluorescence values were plotted over time. All linear values were included in the growth rate calculation, while lag and stationary phase signals were excluded. The slope of the linear regression between the logarithm of fluorescence (or cell number) and time in an exponentially growing culture represents $\mu$. In principle, it is possible to calculate growth rate from 2 data points, but it is advisable to collect a minimum of 3 data points in a series while the culture is growing exponentially (Wood et al. 2005). The mean square error between measured and calculated fluorescence was summed and minimized by the Solver module of Microsoft Excel to optimize stepwise the growth rate estimate. The module's settings were: maximum time $=100 \mathrm{~s}$, iterations $=100$, precision $=0.000001$, tolerance $=5$, convergence $=0.001$, linear estimation, forward differences and Newton algorithm. This calculation was performed for each individual incubation replicate. The replicate growth rates were then averaged.

Chl a concentration. Twenty to $40 \mathrm{ml}$ of cell suspension were filtered onto Whatman GF/F glass microfibre filters and frozen at $-80^{\circ} \mathrm{C}$ for at least $24 \mathrm{~h}$. The filters were homogenized with glass micro-beads (POTTER glass homogenizer, Braun Biotech International) to improve the pigment extraction (Schumann et al. 2005). Each filter was incubated with $3 \mathrm{ml} \mathrm{100 \%}$ $\mathrm{N}, \mathrm{N}$-dimethylformamide for $24 \mathrm{~h}$ in a refrigerator with occasional vortex mixing. Afterwards, the samples were centrifuged and the chl a concentration in the supernatant was quantified photometrically (Porra et al. 1989). If the filters still exhibited a greenish colour after the first extraction, a second extraction was performed and the resulting chl a concentration was added. If the second value made up more than $10 \%$ of the first extraction result, a third extraction was performed.

Organic carbon content. Twenty to $40 \mathrm{ml}$ of cell suspensions were filtered onto precombusted $(5 \mathrm{~h}$ at $450^{\circ} \mathrm{C}$ ) Whatmann $\mathrm{GF} / \mathrm{F}$ glass microfiber filters and dried at $60^{\circ} \mathrm{C}$ for $24 \mathrm{~h}$. Carbon concentrations were determined in a CN analyzer (Vario EL, Elementar Analysensysteme) after Verardo et al. (1990).

Cell length determination. Fifty to 100 cells were photographed for cell length measurements (Olympus
IX 70, objective UPlanApo 60 NA 1.2 W). Cell lengths are given as medians.

Changing pigmentation. Exponentially growing cultures of Stichococcus sp. (SAG 2060), 'Chlorella' trebouxioides (SAG 2143) and Synechocystis sp. (PCC 6803) were sampled at regular intervals over $96 \mathrm{~h}$ after an increase in photon flux density from 35-40 $\mu \mathrm{mol}$ $\mathrm{m}^{-2} \mathrm{~s}^{-1}$ to $500 \mu \mathrm{mol} \mathrm{m} \mathrm{m}^{-2} \mathrm{~s}^{-1}$ at $20^{\circ} \mathrm{C}$ with aeration. Subsampling for cell numbers and chl a concentration was performed with a luer-lock canula (neoLab Migge) and syringe (B. Braun Melsungen). Abundance and chl a concentration were determined as described above.

\section{RESULTS}

\section{Measuring range}

Measuring range and detection limit can be varied by changing the light source intensity (LSI) within an experiment, i.e. raising the LSI caused linearly increasing fluorescence signals (Fig. 1). From the slopes of the linear relationships between chl a fluorescence and cell number or biomass at a constant LSI (here: Step 3), the lower and upper detection limits for each investigated microalgal species were calculated (Table 2). For non-linear regressions, only lower detection limits were calculated from the respective exponential curve fittings. As fast-growing phototrophic microorganisms might exceed the maximal fluorescence value of $1700 \mathrm{mV}$ within a few days, a decrease in LSI will allow the extension of the growth experiments to gain a maximum set of fluorescence values for the calculation of growth rates. In contrast, it is advisable to measure growth rates of slow-growing taxa at increased LSI.

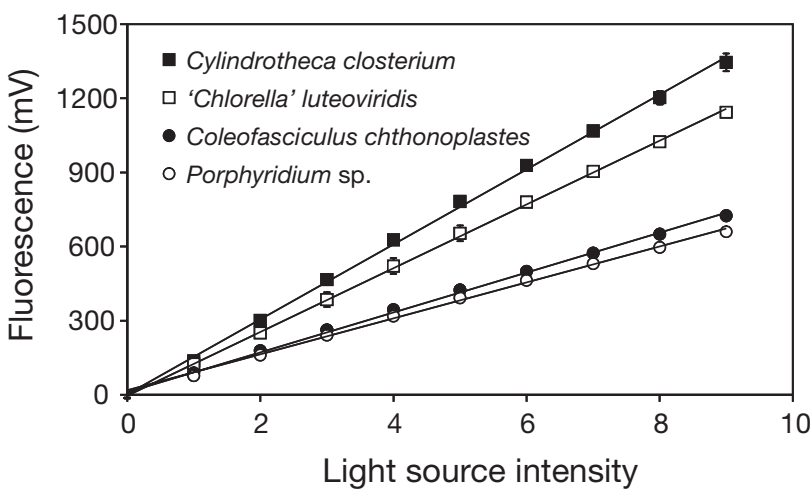

Fig. 1. Chl a fluorescence $(\mathrm{mV})$ as function of light source intensity (setting 1 to 9 ). For all regressions, $\mathrm{R}^{2}>0.99$. Cylindrotheca closterium (ROS-KD 10), 'Chlorella' luteoviridis (SAG 2196), Coleofasciculus chthonoplastes (ROS-WW 11) and Porphyridium sp. (JW 4126) 
Table 1. Species, taxonomic assignment, strain number and morphological characteristics of the investigated microalgae. PCC: Pasteur culture collection of cyanobacteria, Paris; ROS: University of Rostock culture collection; UTEX: University of Texas at Austin culture collection of algae; JW: John West culture collection, University of Melbourne; SAG: University of Göttingen culture collection of algae

\begin{tabular}{|lccl|}
\hline Species & Taxonomic assignment & Strain & Morphological characteristics \\
\hline Synechocystis sp. & Chroococcales & PCC 6803 & Unicellular, buoyant \\
Coleofasciculus chthonoplastes & Oscillatoriales & ROS-WW 11 & Benthic, filamentous \\
Coleofasciculus chthonoplastes & Oscillatoriales & ROS-WW 6 & Benthic, filamentous \\
Dixoniella grisea & Rhodellophyceae & UTEX 2320 & Colony-forming \\
Porphyridium sp. & Porphyridiophyceae & JW 4126 & Unicellular \\
'Chlorella' luteoviridis & Trebouxiophyceae & SAG 2196 & Unicellular \\
'Chlorella' trebouxioides & Trebouxiophyceae & SAG 2142 & Unicellular, adhering \\
'Chlorella' trebouxioides & Trebouxiophyceae & SAG 2143 & Unicellular, adhering \\
Stichococcus sp. & Trebouxiophyceae & SAG 2059 & Unicellular \\
Stichococcus sp. & Trebouxiophyceae & SAG 2060 & Unicellular \\
Desmodesmus subspicatus & Chlorophyceae & ROS-DZBK 33 & 4-cell coenobiae \\
Nitzschia cf. aurariae & Bacillariophyceae & ROS-KD 03 & Benthic, adhering, chain-forming \\
Cylindrotheca closterium & Bacillariophyceae & ROS-KD 10 & Benthic, adhering \\
\hline
\end{tabular}

Table 2. Lower and upper detection limits (abundance in $10^{3} \mathrm{~cm}^{-2}$, carbon biomass in $\mu \mathrm{g} \mathrm{C} \mathrm{cm}{ }^{-2}$, chl a concentration in ng cm ${ }^{-2}$ ), details of regression (slope [fluorescence units per biomass parameter], coefficient of determination $\left[\mathrm{R}^{2}\right]$ ), cell-specific chl $a$ content (fg cell ${ }^{-1}$ ) and average cell length $(\mu \mathrm{m})$ of the investigated strains. nd: not determined

\begin{tabular}{|c|c|c|c|c|c|c|c|c|c|c|c|}
\hline \multirow{2}{*}{ Species } & \multirow{2}{*}{ Strain } & \multicolumn{3}{|c|}{ Lower detection limit } & \multicolumn{3}{|c|}{ Upper detection limit } & \multicolumn{2}{|c|}{ Regression } & \multicolumn{2}{|c|}{ Morphology } \\
\hline & & Abundance & Carbon & Chl a & Abundance & Carbon & Chl a & Slope & $\mathrm{R}^{2}$ & Chl a & Length \\
\hline Synechocystis sp. & PCC 6803 & 465 & nd & nd & nd & nd & nd & Non-linear & 0.99 & 39 & 4 \\
\hline $\begin{array}{l}\text { Coleofasciculus } \\
\text { chthonoplastes }\end{array}$ & ROS-WW 11 & nd & 2 & nd & nd & 40 & nd & Non-linear & 0.99 & 828 & 7 \\
\hline $\begin{array}{l}\text { Coleofasciculus } \\
\text { chthonoplastes }\end{array}$ & ROS-WW 6 & 42 & nd & 66 & nd & nd & nd & Non-linear & 0.95 & 791 & 10 \\
\hline Dixoniella grisea & UTEX 2320 & nd & 1 & 10 & nd & 39 & 950 & Non-linear & 0.99 & nd & 12 \\
\hline Porphyridium sp. & JW 4126 & 12 & nd & $33^{\mathrm{a}}$ & 198 & nd & $560^{\mathrm{a}}$ & 0.12 & 0.99 & 2830 & 11 \\
\hline $\begin{array}{l}\text { 'Chlorella' } \\
\text { luteoviridis }\end{array}$ & SAG 2196 & 12 & nd & $11^{\mathrm{a}}$ & 199 & nd & $191^{\mathrm{a}}$ & 0.12 & 0.96 & 510 & 7 \\
\hline $\begin{array}{l}\text { 'Chlorella' } \\
\text { trebouxioides }\end{array}$ & SAG 2142 & 5 & nd & $1^{\mathrm{a}}$ & 93 & nd & $23^{\mathrm{a}}$ & 0.05 & 0.99 & 246 & 6 \\
\hline $\begin{array}{l}\text { 'Chlorella' } \\
\text { trebouxioides }\end{array}$ & SAG 2143 & 17 & nd & $7^{a}$ & 281 & nd & $127^{a}$ & 0.17 & 0.99 & 754 & 9 \\
\hline Stichococcus sp. & ROS-47/4 & & & & & & & & & & \\
\hline SAG 2059 & 12 & nd & $3^{\mathrm{a}}$ & 212 & nd & $47^{\mathrm{a}}$ & 0.12 & 0.99 & 140 & 6 & \\
\hline Stichococcus sp. & SAG 2060 & 13 & nd & $3^{\mathrm{a}}$ & 219 & nd & $59^{\mathrm{a}}$ & 0.13 & 0.99 & 630 & 6 \\
\hline $\begin{array}{l}\text { Desmodesmus } \\
\text { subspicatus }\end{array}$ & ROS-DZBK 33 & 10 & nd & $9^{a}$ & 163 & nd & $147^{\mathrm{a}}$ & 0.10 & 0.99 & 890 & 5 \\
\hline $\begin{array}{l}\text { Nitzschia cf. } \\
\text { aurariae }\end{array}$ & ROS-KD 03 & 7 & nd & $9^{\mathrm{a}}$ & 92 & nd & $154^{\mathrm{a}}$ & 0.05 & 0.99 & 1630 & ca. 8 \\
\hline $\begin{array}{l}\text { Cylindrotheca } \\
\text { closterium }\end{array}$ & ROS-KD 10 & 1 & nd & $3^{\mathrm{a}}$ & 16 & nd & $57^{a}$ & 0.01 & 0.97 & 3520 & ca. 61 \\
\hline
\end{tabular}

\section{Linear relationship between chl a fluorescence and biomass parameters}

The regression between fluorescence and abundance was linear for green algae, diatoms and the red alga Porphyridium sp. (Fig. 2A, B), as reflected in high coefficients of determination: $\mathrm{R}^{2}>0.96$ (Table 2). In contrast, the cyanobacteria Synechocystis sp. and
Coleofasciculus chthonoplastes showed a non-linear relationship between fluorescence and abundance (Fig. 2C) with an $\mathrm{R}^{2}$ of 0.99 and 0.95 , respectively. The fluorescence signal of filamentous C. chthonoplastes was additionally calibrated against carbon and chl a concentration and showed a non-linear relationship with an $\mathrm{R}^{2}$ of 0.99 (Fig. 3, Table 2). Further, the relationship between fluorescence and biomass equiva- 


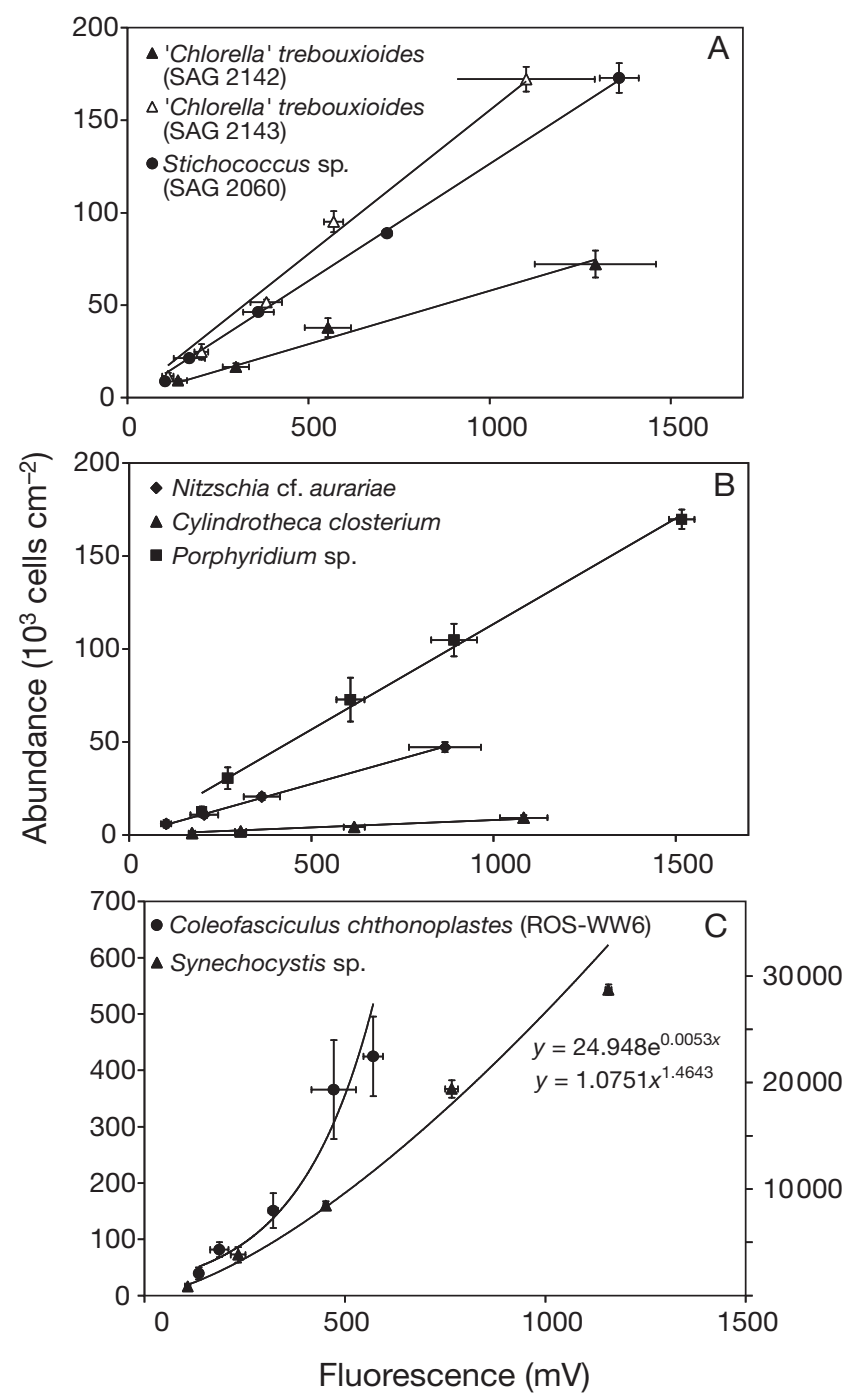

Fig. 2. Relationship between abundance $\left(10^{3}\right.$ cells $\mathrm{cm}^{-2}$; mean $\pm \mathrm{SD}, \mathrm{n}=3$ ) and chl a fluorescence $(\mathrm{mV})$. (A) 'Chlorella' trebouxioides (SAG 2142 and 2143) and Stichococcus sp. (SAG 2060); (B) Nitzschia cf. aurariae (ROS-KD 03), Cylindrotheca closterium (ROS-KD 10) and Porphyridium sp. (JW 4126); and (C) Coleofasciculus chthonoplastes (ROS-WW 6) (primary y-axis) and Synechocystis sp. (PCC 6803) (secondary $y$-axis)

lents (carbon, chl a) of the colony-forming Dixoniella grisea was non-linear with $\mathrm{R}^{2}=0.99$ (Fig. 3, Table 2). Each data set was normalized to an area $\left(\mathrm{cm}^{-2}\right)$ instead of a volume because chl a fluorescence was detected at the bottom of the petri dishes.

\section{Isolate-specific fluorescence and detection limits}

The 6 investigated green algae showed similar cellspecific fluorescence, although cell size ( 5 to $9 \mu \mathrm{m}$ ) and cell-specific chl a concentrations (140 to $1060 \mathrm{fg} \mathrm{chl} \mathrm{a}$ cell ${ }^{-1}$ ) differed profoundly (Table 2). The mean lower
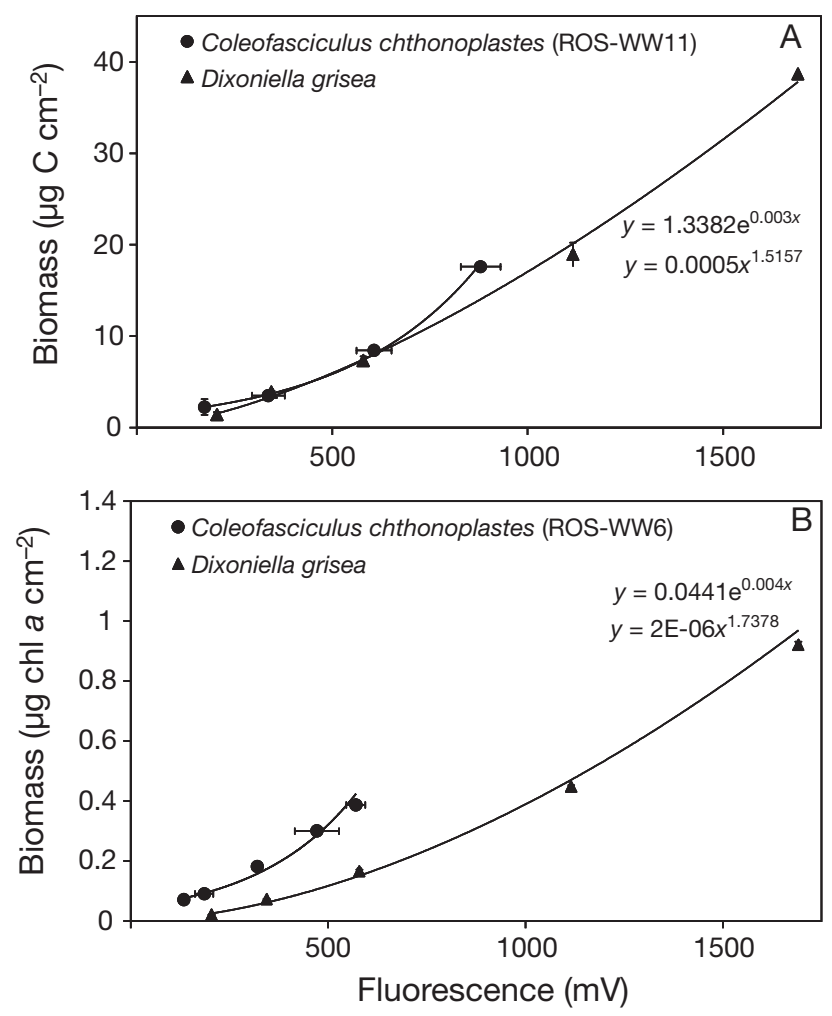

Fig. 3. (A) Correlation between cell-specific carbon concentration $\left(\mu \mathrm{g} \mathrm{cm}^{-2}\right.$; mean $\left.\pm \mathrm{SD}, \mathrm{n}=3\right)$ and chl a fluorescence. Coleofasciculus chthonoplastes (ROS-WW 11) and Dixoniella grisea (UTEX 2320). (B) Cell-specific chl a concentration ( $\mu \mathrm{g}$ $\mathrm{cm}^{-2}$; mean $\pm \mathrm{SD}, \mathrm{n}=3$ ) as function of $\mathrm{chl}$ a fluorescence. Coleofasciculus chthonoplastes (ROS-WW 6) and Dixoniella grisea (UTEX 2320)

detection limit accounted for $12 \times 10^{3}$ cells $\mathrm{cm}^{-2}$ while the mean upper detection limit was $195 \times 10^{3}$ cells $\mathrm{cm}^{-2}$. The unicellular red alga Porphyridium sp. showed cell-specific fluorescence and detection limits in the same order of magnitude as the green algae, although its chl a concentration was twice as high (2830 fg chl a cell ${ }^{-1}$ ) and cells were larger $(11 \mu \mathrm{m})$. The 2 investigated diatoms differed in their morphological characteristics. Cylindrotheca closterium had extremely large cells with an average length of $61 \mu \mathrm{m}$ and a high chl a concentration (3520 fg chl a cell ${ }^{-1}$ ), and thus exhibited the lowest detection limits among the investigated isolates. Nitzschia cf. aurariae had smaller cells $(8 \mu \mathrm{m})$ and a lower chl a concentration (1630 fg chl a cell ${ }^{-1}$ ), with a lower detection limit of $7 \times$ $10^{3}$ cells $\mathrm{cm}^{-2}$. The 2 investigated Cyanobacteria also differed in their morphological characteristics: Synechocystis sp. had small cells $(4 \mu \mathrm{m})$, a low chl a concentration of $39 \mathrm{fg} \mathrm{chl} \mathrm{a} \mathrm{cm}^{-2}$ and an upper detection limit of $465 \times 10^{3}$ cells cm$~^{-2}$, while filamentous Coleofasciculus chthonoplastes exhibited larger cells, a chl a concentration around $800 \mathrm{fg} \mathrm{chl} \mathrm{a} \mathrm{cm}^{-2}$ and an intermedi- 
ate detection limit of $42 \times 10^{3}$ cells cm $\mathrm{cm}^{-2}$ (Fig. 2C). Coleofasciculus chthonoplastes and Dixoniella grisea showed detection limits of 1 to $2 \mu \mathrm{g} \mathrm{C} \mathrm{cm}{ }^{-2}$ and $66 \mathrm{ng}$ chl a $\mathrm{cm}^{-2}$, respectively (Table 2 ).

Based on the cell-specific chl a concentration (Table 2) and the fact that cell numbers correlated linearly with the fluorescence signal (Fig. 2A, B), chl aspecific detection limits were calculated for all unicellular species to illustrate taxon-specific differences (Table 2).

\section{Growth rates}

The setup of in vivo growth fluorometry described here was capable of detecting growth rates between 0.17 and $1.09 \mathrm{~d}^{-1}$ with SD around $10 \%$ within the given adjustments (data not shown). These growth rates equal doubling times of 98 and 15 h, respectively. Fast growing microorganisms exceeded the maximal fluorescence value of $1700 \mathrm{mV}$ in $<3 \mathrm{~d}$. However, a decrease in exciting LSI will allow the extension of the growth experiments to gain a maximum set of fluorescence values for the calculation of the exponential growth rate.

\section{Acclimation to changed radiation conditions}

Exposure to a strong increase in photon flux density resulted in a rapid down-regulation of chl a concentrations in Stichococcus sp., 'Chlorella' trebouxioides and Synechocystis sp. (Fig. 4). The chl a concentrations of the green algal strains at 35 to $40 \mu \mathrm{mol} \mathrm{m} \mathrm{m}^{-2} \mathrm{~s}^{-1}$ were down-regulated within $24 \mathrm{~h}$ after exposure to $500 \mu \mathrm{mol}$

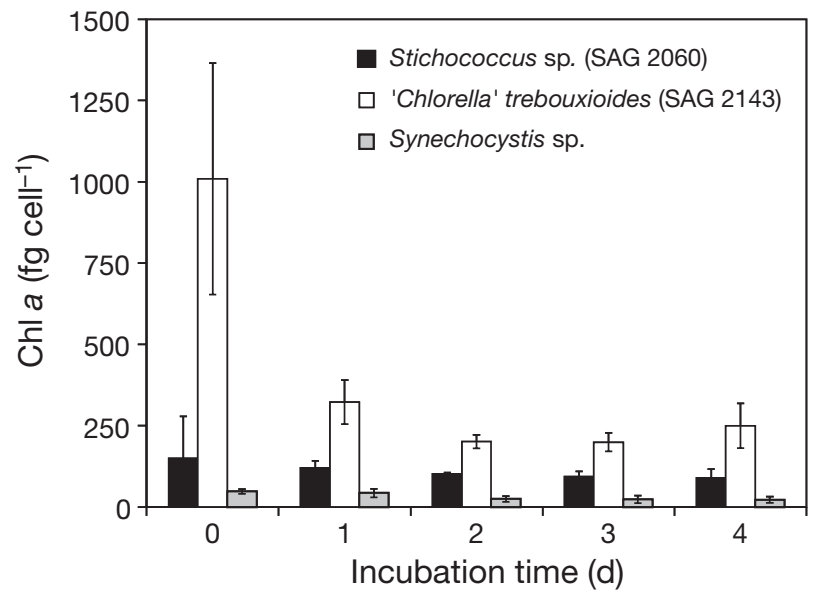

Fig. 4. Cell-specific chl a content (fg chl a cell ${ }^{-1}$, mean $\pm \mathrm{SD}$, $\mathrm{n}=3$ ) after an increase in photon flux density from 40 to $500 \mu \mathrm{mol}$ photons $\mathrm{m}^{-2} \mathrm{~s}^{-1}$ (aerated cultures, $20^{\circ} \mathrm{C}, 16 \mathrm{~h}$ light: $8 \mathrm{~h}$ dark cycle). Stichococcus sp. (SAG 2060), 'Chlorella' trebouxioides (SAG 2143) and Synechocystis sp. (PCC 6803) photons $\mathrm{m}^{-2} \mathrm{~s}^{-1}$ to $1 / 3$ of the initial value and remained unchanged over the following $72 \mathrm{~h}$, indicating complete acclimation. The chl a concentration of Synechocystis sp. was down-regulated within $48 \mathrm{~h}$ after high-light exposure, but to a weaker degree, from 48 to $23 \mathrm{fg} \mathrm{chl} \mathrm{a} \mathrm{cell}{ }^{-1}$.

\section{DISCUSSION}

\section{Fluorescence characteristics of the investigated taxa}

Algae are assigned to different taxonomic groups (e.g. van den Hoek et al. 1995) based not only on their phylogenetic affinities, but also on a specific composition of light-harvesting pigments. These compounds can be divided into 3 groups: chlorophylls, phycobiliproteins and carotenoids. Although photosynthetic organisms are taxonomically highly diverse, chl a (absorption maxima at 430 and $662 \mathrm{~nm}$ ) is present ubiquitously (Papageorgiou 2004). In addition, Chlorophyta contain chl $b$, which mainly absorbs radiation around 457 and $645 \mathrm{~nm}$. Bacillariophyceae utilize chl $C$ ( $450 \mathrm{~nm}$ ) and fucoxanthin (446 to $468 \mathrm{~nm}$ ) in addition to chl a for light harvesting (Jeffrey \& Wright 1997). The method presented here uses a peak excitation wavelength of $470 \mathrm{~nm}$ and, thus, excites chlorophylls and fucoxanthin well.

Phycobilisomes serve as the primary light-harvesting antennae for Photosystem II (PSII) in Cyanobacteria and red algae (Sidler 1994) and cover a spectral range where few other light-harvesting systems are functioning (absorption maxima between 570 and $650 \mathrm{~nm})$. Although organisms containing these complexes are able to use a wide range of wavelengths and are capable to photosynthesize at low radiation conditions (Kursar et al. 1981), they are only weakly excited by blue light. Most of the cyanobacterial and red algal chl $a$ is located in the weakly fluorescent Photosystem I, while in other algae, this pigment is mainly associated with PSII. Consequently, the specific pigment composition and localisation in Cyanobacteria and red algae explains well the inefficient excitation at $470 \mathrm{~nm}$ (Heaney 1978, Schubert et al. 1989) as reflected by the non-linear relationship between fluorescence and biomass (Figs. 2C \& 3). The carotenoids lutein, neoxanthin, violaxanthin and $\beta$-carotene play a central role in photoprotection and, hence, decrease specifically the absorption of blue light by chl $a$, but contribute only slightly to light harvesting (Bassi \& Caffarri 2000).

Jakob et al. (2005) suggested an excitation at $630 \mathrm{~nm}$ for the detection of Cyanobacteria to optimally use the presence of phycocyanin. In contrast to other accessory pigments, phycobilins exhibit fluorescence at 640 to $660 \mathrm{~nm}$ (Gregor \& Marsálek 2005). Based on these 
properties, the excitation wavelengths can be easily modified by using green and/or red LEDs and different filters at the detection diode to make the presented method for Cyanobacteria as sensitive as for green algae and diatoms.

\section{Measuring range and detection limits}

The chl a fluorescence signal detected by the in vivo growth fluorometer is influenced by the exciting LSI, the intracellular concentration of chl $a$ and the light scattered and absorbed by the cells. The fluorescence signal increases linearly with rising LSI and (at a fixed LSI) with chl a concentration. As the method measures sedimented instead of suspended cells (Brand et al. 1981), fluorescence of motile phototrophic organisms, such as dinoflagellates, could not be detected. Another limitation of the discussed method may occur for fastgrowing organisms $\left(\mu>1.1 \mathrm{~d}^{-1}\right)$ cultured under lightdark cycles. If the obtained fluorescence data set consists of less than 3 values, calculation of the respective growth rate can be inaccurate. More frequent measurements at shorter intervals $(<24 \mathrm{~h})$ are only possible for cultures grown under continuous light. Synchronized cultures (microalgae cultivated under a light-dark cycle) typically exhibit saw-tooth patterns in their growth rate when measurements are performed at short intervals.

High abundances may cause re-absorption, selfshading and scattering; thus, the relationship between fluorescence signal and chl a content may not be linear anymore. If green algal cells with a 2-dimensional size of about $70 \mu^{2}$ and an abundance of $195 \times 10^{3}$ cells $\mathrm{cm}^{-2}$ (mean upper detection limit for Chlorophyta) are transferred into the petri dishes, the cells cover only $12 \%$ of the bottom. Therefore, the effects of self-shading and re-absorption can be neglected for unicellular organisms showing comparable detection limits. Besides quality (characteristic absorption wavelengths) of light-harvesting pigments, the quantity of cell-specific chl $a$, combined with cell size and shape, influence the intensity of PSII fluorescence and, therefore, the lower detection limit. The most sensitive lower detection limit $\left(10^{3}\right.$ cells $\left.\mathrm{cm}^{-2}\right)$ was measured for Cylindrotheca closterium. The combination of large cells, very high cell-specific chl a content and the intensive fluorescence response due to additional $\mathrm{chl} C$ and fucoxanthin accounted for that result. In contrast, comparison of the 2 investigated 'Chlorella' trebouxioides strains SAG 2142 and SAG 2143 indicated strong differences in detection limit because of deviating cell-specific chl a contents. Furthermore, the smaller organism with less chl a (SAG 2142) exhibited a much lower detection limit than the larger taxa (SAG
2143) with a $3 \times$ higher chl a concentration (Table 2). The latter example demonstrates that cell size and chl a content are not always linearly correlated with cell-specific fluorescence. Therefore, concentration of all pigments absorbing at $470 \mathrm{~nm}$ such as chl $b$, fucoxanthin or phycoerythrin should be taken into account.

Self-shading occurs massively for the small planktonic Synechocystis sp. Cells are easily resuspended or even remain buoyant in the water column. Thus, only a small fraction of cells could be detected at the bottom, contributing to a diminished fluorescence signal in contrast to very high abundances. Moreover, this species contained only $39 \mathrm{fg}$ chl a cell ${ }^{-1}$, the lowest concentration among the investigated taxa. The high lower detection limit compared to eukaryotic microalgae is additionally related to the specific fluorescence characteristics of Cyanobacteria (see above). In contrast, the cyanobacterium Coleofasciculus chthonoplastes had larger cells forming individual or bundled trichomes of $>20$ cells. These cells had a much higher cell-specific chl a content (Table 2) and adhered very easily to the bottom of the petri dish. Even though the present excitation wavelength of $470 \mathrm{~nm}$ is not optimal for Cyanobacteria, growth rates of C. chthonoplastes could be determined at low to intermediate abundances in particular for slow-growing isolates and at high excitation irradiances (Pattanaik et al. 2008).

Porphyridium sp. is unicellular, exhibits a very high chl a concentration and contains phycoerythrin (A. Eggert unpubl. data) which slightly absorbs at $470 \mathrm{~nm}$. This species showed a linear relationship between cell number and fluorescence. In contrast, the colony-forming Dixoniella grisea exhibited a curve-like relationship of fluorescence to chl a and carbon concentrations due to self-shading at higher concentrations.

Using the present method, calibration of fluorescence to cell count is not needed for green algae, diatoms or the unicellular red alga Porphyridium sp. The data presented here clearly indicate a rather high variability of fluorescence properties within a taxonomical group. The combination of pigment composition and concentration as well as morphology is essential for the applicability of the discussed method. As the excitation wavelength is not ideal for Cyanobacteria and red algae, calibration towards other biomass equivalents is recommended to determine the specific detection limits and the applicability of the presented method.

\section{Acclimation to radiation conditions}

Pre-incubation under specific abiotic conditions is advisable to complete acclimation before beginning measurements of in vivo growth rates as discussed in the present study. Photoacclimation typically includes 
changes in pigment contents, fluorescence characteristics $\left(F_{\mathrm{v}} / F_{\mathrm{m}}\right.$ and non-photochemical quenching, NPQ) or cell size, and proceeds in time scales from hours to days (Fisher et al. 1996, Robinson et al. 1997, Ritz et al. 2000). Although the complete down-regulation of chl a content in Stichococcus sp., C. trebouxioides and Synechococcus sp. after a strong increase in photon flux density occurred within 24 to 48 h (Fig. 4), we recommend pre-incubation for at least $3 \mathrm{~d}$ under controlled culture conditions.

\section{Importance of in vivo growth rates}

From an ecological perspective, growth rate represents the most relevant process to describe the performance of species in an ecosystem because it integrates all intracellular (positive and negative) acclimation processes. A multifactorial in vivo analysis of growth allows evaluation of tolerance limits, growth optima and acclimation abilities of specific microalgae and, hence, facilitates the interpretation of natural distributions. Knowledge of physiological limits is necessary to estimate and understand distribution limits within an unknown community, i.e. a competitive situation. Additionally, the shape of the growth rate curve in dependence of abiotic factors characterizes a species as steno- or euryoecious, which definitively affects its competitive strength. An easy, fast and inexpensive method to determine growth rates, such as presented here, provides the opportunity to examine multifactorial approaches in more detail (e.g. Eggert et al. 2007) and in comparison to the ecological niche. In the context of ongoing population and species extinction due to anthropologic changes of ecosystems, the description of physiological niches is imperative to explain species occurrence (hindsight) and propagation or displacement (forecast). So far, the method of in vivo growth fluorometry has been successfully applied to Cyanobacteria (Garcia-Pichel et al. 1998, Pattanaik et al. 2008), red algae (Eggert et al. 2007), biofilm-forming aeroterrestrial green algae (Häubner et al. 2006, Gustavs et al. in press) and diatoms (Clavero et al. 2000, Karsten et al. 2006).

Acknowledgements. We gratefully acknowledge financial support through the Deutsche Forschungsgemeinschaft (KA 899/13-1/2, KA 899/1/2/3 and EG 151/1-2). We thank B. Pattanaik, E. Lawrenz, S. Raimund and M. Rickler for providing data and J. Buss for excellent technical assistance.

\section{LITERATURE CITED}

Bassi R, Caffarri S (2000) Lhc proteins and the regulation of photosynthetic light harvesting function by xanthophylls. Photosynth Res 64:243-256
Becker EW (1994) Microalgae: biotechnology and microbiology. Cambridge University Press, Cambridge

Brand LE, Guillard RRL, Murphy LS (1981) A method for the rapid and precise determination of acclimated phytoplankton reproduction rates. J Plankton Res 3:193-201

Brown LM, Gargantini I, Brown DJ, Atkinson HJ, Govindarajan J, Vanlerberghe GC (1989) Computer-based image analysis for the automated counting and morphological description of microalgae in culture. J Appl Phycol 1:211-225

Butterwick C, Heaney SI, Talling JF (1982) A comparison of eight methods for estimating the biomass and growth of planktonic algae. Eur J Phycol 17:69-79

> Clavero E, Hernandez-Marine M, Grimalt JO, Garcia-Pichel F (2000) Salinity tolerance of diatoms from thalassic hypersaline environments. J Phycol 36:1021-1034

Eggert A, Raimund S, Michalik D, West J, Karsten U (2007) Ecophysiological performance of the primitive red alga Dixoniella grisea (Rhodellophyceae) to irradiance, temperature and salinity stress: growth responses and the osmotic role of mannitol. Phycologia 46:22-28

- Fisher T, Minnaard J, Dubinsky Z (1996) Photoacclimation in the marine alga Nannochloropsis sp (Eustigmatophyte): a kinetic study. J Plankton Res 18:1797-1818

> Garcia-Pichel F, Sherry ND, Castenholz RW (1992) Evidence for an ultraviolet sunscreen role of the extracellular pigment scytonemin in the terrestrial cyanobacterium Chlorogloeopsis sp. Photochem Photobiol 56:17-23

Garcia-Pichel F, Nubel U, Muyzer G (1998) The phylogeny of unicellular, extremely halotolerant cyanobacteria. Arch Microbiol 169:469-482

> Gregor J, Maršálek B (2005) A simple in vivo fluorescence method for the selective detection and quantification of freshwater cyanobacteria and eukaryotic algae. Acta Hydrochim Hydrobiol 33:142-148

Guillard RRL (1975) Culture of phytoplankton for feeding marine invertebrates. In: Smith WL, Chanley MH (eds) Culture of marine invertebrate animals. Plenum Press, New York, p 29-60

Gustavs L, Eggert A, Michalik D, Karsten U (in press) Physiological and biochemical responses of aeroterrestrial green algae (Trebouxiophyceae) to osmotic and matric stress. Protoplasma

Häubner N, Schumann R, Karsten U (2006) Aeroterrestrial microalgae growing in biofilms on facades: response to temperature and water stress. Microb Ecol 51:285-293

Heaney SI (1978) Some observations on the use of the in vivo fluorescence technique to determine chlorophyll $a$ in natural populations and culture of freshwater phytoplankton. Freshw Biol 8:115-126

Jakob T, Schreiber U, Kirchesch V, Langner U, Wilhelm C (2005) Estimation of chlorophyll content and daily primary production of the major algal groups by means of multiwavelength-excitation PAM chlorophyll fluorometry: performance and methodological limits. Photosynth Res 83: 343-361

Jeffrey SW, Wright SW (1997) Phytoplankton pigments in oceanography. UNESCO Publishing, Paris

Karsten U, Klimant I, Holst G (1996) A new in vivo fluorimetric technique to measure growth of adhering phototrophic microorganisms. Appl Environ Microbiol 62:237-243

- Karsten U, Schumann R, Rothe S, Jung I, Medlin L (2006) Temperature and light requirements for growth of two diatom species (Bacillariophyceae) isolated from an Arctic macroalga. Polar Biol 29:476-486

Kruskopf M, Flynn KJ (2006) Chlorophyll content and fluorescence responses cannot be used to gauge reliably phyto- 
plankton biomass, nutrient status or growth rate. New Phytol 169:525-536

Kursar TA, Swift H, Alberte RS (1981) Morphology of a novel cyanobacterium and characterization of light harvesting complexes from it: implications for phycobiliprotein evolution. Proc Natl Acad Sci USA 78:6888-6892

MacArthur RH, Wilson EO (1967) The theory of island biogeography. Princeton University Press, Princeton, NJ

Papageorgiou GC (2004) Fluorescence of photosynthetic pigments in vitro and in vivo. In: Papageorgiou GC, Govindjee (eds) Chlorophyll a fluorescence: a signature of photosynthesis. Springer, Dordrecht, p 43-63

Pattanaik B, Roleda MY, Schumann R, Karsten U (2008) Isolate-specific effects of ultraviolet radiation on photosynthesis, growth and mycosporine-like amino acids in the microbial mat-forming cyanobacterium Microcoleus chthonoplastes. Planta 227:907-916

Porra RJ, Thompson WA, Kriedemann PE (1989) Determination of accurate extinction coefficients and simultaneous equations for assaying chlorophylls $a$ and $b$ extracted with four different solvents: verification of the concentration of chlorophyll standards by atomic absorption spectroscopy. Biochim Biophys Acta 975:384-394

Ritz M, Thomas JC, Spilar A, Etienne AL (2000) Kinetics of photoacclimation in response to a shift to high light of the red alga Rhodella violacea adapted to low irradiance. Plant Physiol 123:1415-1425

Robinson DH, Kolber Z, Sullivan CW (1997) Photophysiology and photoacclimation in surface sea ice algae from McMurdo Sound, Antarctica. Mar Ecol Prog Ser 147: 243-256

Schubert H, Schiewer U, Tschirner E (1989) Fluorescence characteristics of cyanobacteria (blue-green algae). J Plankton Res 11:353-359

Editorial responsibility: Josep Gasol, Barcelona, Spain
Schumann R, Häubner N, Klausch S, Karsten U (2005) Chlorophyll extraction methods for the quantification of green microalgae colonizing building facades. Int Biodeterior Biodegrad 55:213-222

Sidler WA (1994) Phycobilisome and phycobiliprotein structures. In: Bryant DA (ed) The molecular biology of cyanobacteria. Kluwer Academic Publishers, Dordrecht, p 139-216

Siegesmund MA, Johansen JR, Karsten U, Friedl T (2008) Coleofasciculus gen. nov. (Cyanobacteria): morphological and molecular criteria for revision of the genus Microcoleus Gomont. J Phycol 44:1572-1585

Starr RC, Zeikus JA (1993) Utex: the culture collection of algae at the University of Texas at Austin. 1993 list of cultures. J Phycol 29:1-106

Stein JR (1973) Handbook of phycological methods: culture methods and growth measurements. Cambridge University Press, Cambridge

van den Hoek C, Mann DG, Jahns HM (1995) Algae: an introduction to phycology. Cambridge University Press, Cambridge

Verardo DJ, Froelich PN, McIntyre A (1990) Determination of organic carbon and nitrogen in marine sediments using the Carlo Erba Na-1500 analyzer. Deep-Sea Res I 37: 157-165

Wood AM, Everroad RC, Wingard LM (2005) Measuring growth rates in microalgal cultures. In: Andersen RA (ed) Algal culturing techniques. Elsevier Academic Press, Burlington, MA, p 269-285

Wright SW, Jeffrey SW, Mantoura RFC (1997) Evaluation of methods and solvents for pigment extraction. In: Jeffrey SW, Mantoura RFC, Wright SW (eds) Phytoplankton pigments in oceanography: guidelines to modern methods. Monographs on oceanographic methodology, Vol 10. UNESCO Publishing, Paris, p 261-282

Submitted: September 3, 2007; Accepted: February 23, 2009 Proofs received from author(s): April 9, 2009 